\title{
COMMENT
}

\section{Reponse to Send et al. telomere length in newborns is related to maternal stress during pregnancy}

\author{
Kyle C. Esteves ${ }^{1}$, Christopher W. Jones ${ }^{2}$ and Stacy S. Drury ${ }^{1,2}$ \\ Neuropsychopharmacology (2018) 43:2163; https://doi.org/10.1038/s41386-018-0077-x
}

\section{INTRODUCTION}

We were initially very enthusiastic about the recent report by Send and colleagues [1], particularly given its consistency with previous studies [2]. However, more careful reading revealed several critical concerns with significant relevance to the field. First, although the authors report sex differences in cord blood telomere length (TL), they fail to account for this in their analytic models. A significant difference by sex in the primary outcome (i.e., TL) necessitates, at the very least, controlling for sex analytically in all models. This is especially important given the robust evidence of sex differences in prenatal programming across species and offspring outcomes $[3,4]$. Furthermore, the authors fail to report the race/ethnicity frequencies of their cohort, aside from Caucasians, and do not control for race in analyses, despite reported race differences in TL [5].

The second concern is of TL measurement methodology. While it is important that the authors address TL differences resulting from DNA isolation kit, the actual comparison of samples is unclear. The authors report longer cord blood TL with the Chemagen module isolated DNA relative to the Qiagen $\mathrm{GmbH}$, however only 14 DNA samples were isolated using Qiagen $\mathrm{GmbH}$. It is unknown if the same cord blood samples were extracted using both methods and then assayed or if a simple $t$-test was conducted. Secondly, the authors report significant batch effects for the qPCR assays, yet fail to offer explanation. If 128 samples were repeated on two separate occasions, perhaps a correction factor could be used. In addition, only a coefficient of variation (CV) was reported for the 128 repeated samples, no CV was reported for the entire TL database, and no threshold of quality was reported, a standard quality control outcome. Furthermore, while the authors residualized newborn TL for batch effects, the same standard of genomic DNA from the K562 cell line was used and therefore an indication of the batch variability may be determined by differences in the standard curves suggesting that the batch effect was the result of user error or in reagents (which is unlikely) used between plates.

In short, although the conceptual framework for the report by Send and colleagues [1] has merit, the methodology regarding TL measurements and the failure to control for infant sex, given significant differences, is puzzling. Defining the true relationship between TL and maternal prenatal stress has substantial significance, both for our understanding of the biological mechanisms through which early adversity is embedded and because telomere attrition across the life span is related to initial TL [6]. With the explosive growth in telomere studies, researchers need to ensure the most stringent methodologic assays and statistical analyses, ideally using significant sample sizes and longitudinal data to protect against false positive findings and intra-assay variability.

\section{REFERENCES}

1. Send TS, Gilles M, Codd V, Wolf I, Bardtke S, Streit F, et al. Telomere length in newborns is related to maternal stress during pregnancy. Neuropsychopharmacology. 2017;42:2407.

2. Marchetto NM, Glynn RA, Ferry ML, Ostojic M, Wolff SM, Yao R, Haussmann MF. Prenatal stress and newborn telomere length. Am J Obstet \& Gynecol. 2016;215:94-e1.

3. Bale TL. Sex differences in prenatal epigenetic programing of stress pathways. Stress . 2011:14:348-56.

4. Gray SA, Jones CW, Theall KP, Glackin E, Drury SS. Thinking across generations: unique contributions of maternal early life and prenatal stress to infant physiology. J Am Acad Child \& Adolesc Psychiatry. 2017;56:922-9.

5. Drury SS, Esteves K, Hatch V, Woodbury M, Borne S, Adamski A, Theall KP. Setting the trajectory: racial disparities in newborn telomere length. J Pediatr. 2015;166:1181-6.

6. Nordfjäll K, Svenson U, Norrback K-F, Adolfsson R, Lenner P, Roos G. The individual blood cell telomere attrition rate is telomere length dependent. PLoS Genet. 2009;5:e1000375.

\footnotetext{
${ }^{1}$ Department of Psychiatry and Behavioral Sciences, Tulane University School of Medicine, New Orleans, LA, USA and ${ }^{2}$ Department of Neuroscience, Tulane Brain Institute, Tulane University, New Orleans, LA, USA

Correspondence: Kyle C. Esteves (kesteves@tulane.edu)
}

Received: 23 February 2018 Accepted: 28 March 2018

Published online: 27 April 2018 